\title{
COVID-19's Pathways to Human Central Nervous System and Relevant Drug Treatment
}

\author{
Zhaolun Liang ${ }^{1}$ \\ ${ }^{1}$ Pennsylvania State University, Eberly College of Science State College Pennsylvania, 16802, USA
}

\begin{abstract}
COVID-19, also known as Severe Acute Respiratory Syndrome-Coronavirus 2 (SARS-CoV2), is a severe disease. It can cause different types of symptoms including shortness of breath, fever, cough, fatigue and sore throat. Older adults and people who have severe underlying medical conditions like heart or lung disease or diabetes seem to be at higher risk to develop more complex complications due to the infection. Until August 6th, 2020, COVID-19 has caused 700,000 deaths across the Earth; however, the actual death number could be higher than 700,000. COVID-19's origin is still remained unknown, but the speculation is targeted to bats or pangolins. Although COVID-19 is a disease target human's respiratory system, based on the research and clinical cases of COVID-19, evidence shows that COVID-19 can also invade human's central nervous system (CNS).
\end{abstract}

\section{INTRODUCTION}

In search of more than 20 different resources on Pubmed, SciFinder-n and Penn State library, three different sections are included in this review article. The first section is the literature review of COVID-19's invasion to human central nervous system which includes the different examples of invasion of COVID-19 to human nervous system and central nervous system. The second section discussed the specific drug treatment towards COVIDrelevant infection but not only about central nervous system due to the limited number of literatures. The third section includes the personal opinions about COVID-19 invasion to CNS and discussion towards this topic.

\section{COVID-19 Invasion to Human CNS}

Due to the high similarity between COVID-19 and SARSCoV [1] and MERS-CoV [2, 23], COVID-19 has been speculated to cause the infection in human central nervous system by scientists. Theoretically, SARS-CoV2 has the similar transmission pathway with SARS-CoV and MERS-CoV; all of these viruses showed the signs of pneumonia, fever, cough and fatigue. However, COVID19 shows significant signs of fecal-oral transmission which is a relatively rare issue for SARS-CoV and MERSCoV. COVID-19's genome has 6 major ORFs which are common among the coronavirus. Also, the genome sequence of COVID-19 shows the high similarity with SARS-CoV and MERS-CoV (70\%, 40\%, respectively). [26] Also the gene of spike protein on COVID-19 is different with each other; spike protein makes the contact with cell receptors in human body. The difference within $\mathrm{ORFa}$ is also mentioned.

Table1. Comparison between COVID-19, SARS-Cov and MERS-CoV

\begin{tabular}{|l|l|l|l|}
\hline $\begin{array}{l}\text { Common } \\
\text { Symptoms }\end{array}$ & $\begin{array}{l}\text { COVID-19/SARS-CoV2 } \\
\text { fatigue }\end{array}$ & SARS-CoV & MERS-CoV \\
\hline $\begin{array}{l}\text { Respiratory tract } \\
\text { symptoms }\end{array}$ & Lower respiratory signs & $\begin{array}{l}\text { Fever, cough, myalgia } \\
\text { and fatigue }\end{array}$ & $\begin{array}{l}\text { Fever, cough, myalgia and } \\
\text { fatigue }\end{array}$ \\
\hline Receptors & ACE2 & ACE2 & $\begin{array}{l}\text { Upper respiratory signs and } \\
\text { gastrointestinal symptoms }\end{array}$ \\
\hline $\begin{array}{l}\text { Route } \\
\text { Transmission }\end{array}$ & $\begin{array}{l}\text { Airways, contact transmission } \\
\text { and person-to-person } \\
\text { transmission, fecal-oral } \\
\text { transmission }\end{array}$ & $\begin{array}{l}\text { Respiratory droplets } \\
\text { transmission and } \\
\text { person-to-person } \\
\text { transmission }\end{array}$ & Close contact transmission \\
\hline Susceptible & All people & All people & All people \\
\hline
\end{tabular}

*Corresponding author. Email: zb15142@psu.edu 


\begin{tabular}{|l|l|l|l|}
\hline Population & & & \\
\hline Treatment & $\begin{array}{l}\text { Possible treatment includes } \\
\text { medicine injection and } \\
\text { intranasal route }\end{array}$ & $\begin{array}{l}\text { Combination of } \\
\text { lopinavir and ritonavir }\end{array}$ & $\begin{array}{l}\text { Combination of ribavirin } \\
\text { (or ritonavir) and interferon } \\
\text { alpha-2b }\end{array}$ \\
\hline Number of death & 871,000 (September 4,2020) & Around 8908 & 2254 \\
\hline
\end{tabular}

In a published paper in April, a clinical case of a 74year-old Hispanic male [3] shows signs of central nervous system infection. The patient had no history of fever or cough; at the same time, chest radiography discovered the enlarged cardiac silhouette and tortuous aorta, no infiltrates were found at this point. Over the next 4 days, the situation of patient was worsening: chest radiography shows new left basilar densities combined with left lower lobe consolidation. Right basilar densities were found at the same point as well as patchy densities in the right midlung; the patient expired at the day 11. Based on the postmortem examination by Transmission Electron Microscopy, $80 \mathrm{~nm}-100 \mathrm{~nm}$ viral particles in front lobe were identified. More importantly, viral particles were observed in small vesicles in endothelial cells. The appearance of the viral particles in vesicles in endothelial cells is one of the strongest indications of infection in central nervous system. The pathway from brain microvascular endothelial cells into the neural niche is identified in this particular case. Even though the evidence shows COVID-19 may infect human central nervous system, the detailed mechanism still remained unknown at this point.

This is one of the earliest findings and speculation of correlation between infection of central nervous system and COVID-19. However, the literature earlier than this all raised the same concern about probable invasion of central nervous system may cause the failure of respiratory system. The literature pointed out the potential of COVID-19 has similar features to SARS-CoV and MERS-CoV; however, the infections of COVID-19 don't show significant signs to upper airway of human, which indicates the potential of infection to lower respiratory tract of human.[4] However, some authors pointed out the potential of COVID-19 to invade human central nervous system illustrating the COVID-19 could invade peripheral nerve terminal to access central nervous system via the synapse-connected route. [5-7] According the similarity between COVID-19, SARS-CoV and ,MERS-CoV, the main pathway to human should be the angiotensinconverting enzyme 2 (ACE2) or dipeptidyl peptidase 4 (DP4), COVID-19 should be restricted in the lower airway in nasal epithelium. Nevertheless, under the poorly understood circumstance to COVID-19, the virus could pass through epithelium cells to enter the bloodstream then entering the CNS. The medical team who took care of that 74-year-old Hispanic male raised another possibility: In the hematogenous route, viruses gain access by infecting endothelial cells of the blood-brain barrier, epithelial cells of the blood-cerebrospinal fluid barrier in the choroid plexus, or use inflammatory cells as disguise to gain access into the CNS. [3] Furthermore, additional evidence shows the appearance of virus in human cerebrospinal fluid testified the invasion of COVID-19 to human CNS. [8] Also the lab results of mice showed that virus might enter the brain via nose epithelium barrier. [8] Recently, another data presented by medRxiv[9] reported the 78 out of 214 patients have neurologic manifestation, which also affirms the potential possibilities of COVID19 attacking human CNS. Two other possibilities were also raised; the virus could use the spike protein to attack the ACE2 in capillary endothelium. The movement of the COVID-19 virus to the brain via the cribriform plate close to the olfactory bulb can be an additional pathway that could enable the virus to reach and affect the brain.[10] Another experiment conducted in April, 10th found out the correlation between CNS symptoms and lymphocyte levels, platelet counts, and blood urea nitrogen levels compared with those without CNS symptoms.[11] For 7 different group of patients, the patients who have CNS symptoms also experienced lower lymphocyte levels, lower platelet counts and higher level of blood urea. Also, severe infected patients showed signs of increase Creactive proteins and D-dimer levels.

Table2. Clinical Evidence of Sever Infected Patients vs. NonSevere Infected Patients Conducted by Mao et al [11]

\begin{tabular}{|l|l|l|}
\hline & $\begin{array}{l}\text { Severe Infected Patients (Median and } \\
\text { Range Included) }\end{array}$ & $\begin{array}{l}\text { Nonsevere Infected Patients } \\
\text { (Median and Range Included) }\end{array}$ \\
\hline Lymphocyte & $0.7 \times 109 / \mathrm{L}[$ range, $0.1-1.6]$ & $0.9 \times 109 / \mathrm{L}[$ range, $0.2-2.6]$ \\
\hline Platelet & $169.0 \times 109 / \mathrm{L}[$ range, $18.0-564.0]$ & $220.0 \times 109 / \mathrm{L}[$ range, $109.0-576.0]$ \\
\hline Blood Urea Nitrogen & $5.0 \mathrm{mmol} / \mathrm{L}[$ range, $2.3-48.1]$ & $4.4 \mathrm{mmol} / \mathrm{L}[\mathrm{range}, 1.5-19.1]$ \\
\hline C-reactive protein & $37.1 \mathrm{mg} / \mathrm{L}[$ range, $0.1-212.0]$ & $9.4 \mathrm{mg} / \mathrm{L}[\mathrm{range}, 0.2-126.0]$ \\
\hline D-dimer levels & $0.9 \mathrm{mg} / \mathrm{L}[$ range, $0.1-20.0]$ & $0.4 \mathrm{mg} / \mathrm{L}[$ range, $0.2-8.7]$ \\
\hline
\end{tabular}

Patients who suffered neurologic invasion show signs of skeleton muscle symptoms. [11] Upon the studies and research by experts in the neuron science area, another assumption was raised. COVID-19 can enter neurons via a retrograde transsynaptic route via ACE 2 receptors instead of capillary endothelium discussed above; this infection may also cause the infection of thalamus and brain stem. Additionally, hematogenous dissemination may also facilitate the process of infection in lung. [10]

Additionally, the potential psychological problems caused by COVID-19 also raised the attention in scientific area. [24] The articles pointed out the potential stress caused by COVID-19 in the whole society need to be resolved by taking measures. The patients being tested 
positive would experience quarantine, which is not an appropriate situation for psychological development. Psychological intervene is needed for the society. These concerns, on the other hand, are based on clinical evidence and have no scientific proof. At this point, mechanism of COVID-19 invasion may cause psychological problems were discussed in April, 2020 [25]. It can be identified that the stress caused by COVID-19 may cause the overactivation of human hypothalamic-pituitary-adrenal (HPA) axis. Over-activation of HPA axis effectors glucocorticoids and glucocorticoids receptors would cause stress-related symptoms such as amnesia, depression and anxiety.

Almost all of the assumptions raised above mentioned the correlation between infection in CNS and ACE2. ACE2, at the same time, is the main receptor to accept the SARS-CoVs, the spike protein existed on the surface of COVID-19 helps it open the pathway to human inner system. Hence, it could be concluded that the ACE2 pathways should be the main focus for scientists in the future. Capillary endothelium, olfactory pathway, even inflammatory cells could also be the tested site. Although ACE2 are mainly attached to the cell membrane of cells in the lungs, arteries, heart, kidney, and intestines, [12, 13] evidence still shows the sign of ACE2 distribution in human brain which could probably facilitate the process of infection to human CNS. [8]

\section{Drug Treatment of COVID-19 Infection}

Due to the limited amount of literatures about treatment to central nervous system, any relevant treatments towards COVID-19 infection would be covered and discussed. Upon the searching of different treatments, one of which can be seen as the most novel, direct and efficient: using intranasal route to deliver drugs directly into human nervous system. [14] Based on clinical cases of central nervous system infection, brainstem usually is the most concentrated infection site. Hence, intravenous injection drugs need to be used in the treatment. [15] Since most of the route to central nervous system involve the entry of location of blood-brain barrier or via olfactory route, using the intranasal route to enter the central nervous system can bypass the blood-brain barrier via porous cribriform. Therefore, for future treatment, effective and water soluble drugs or medicine should be vaporized then using the intranasal route to directly enter the central nervous system to overcome the blood-brain barrier impediment.

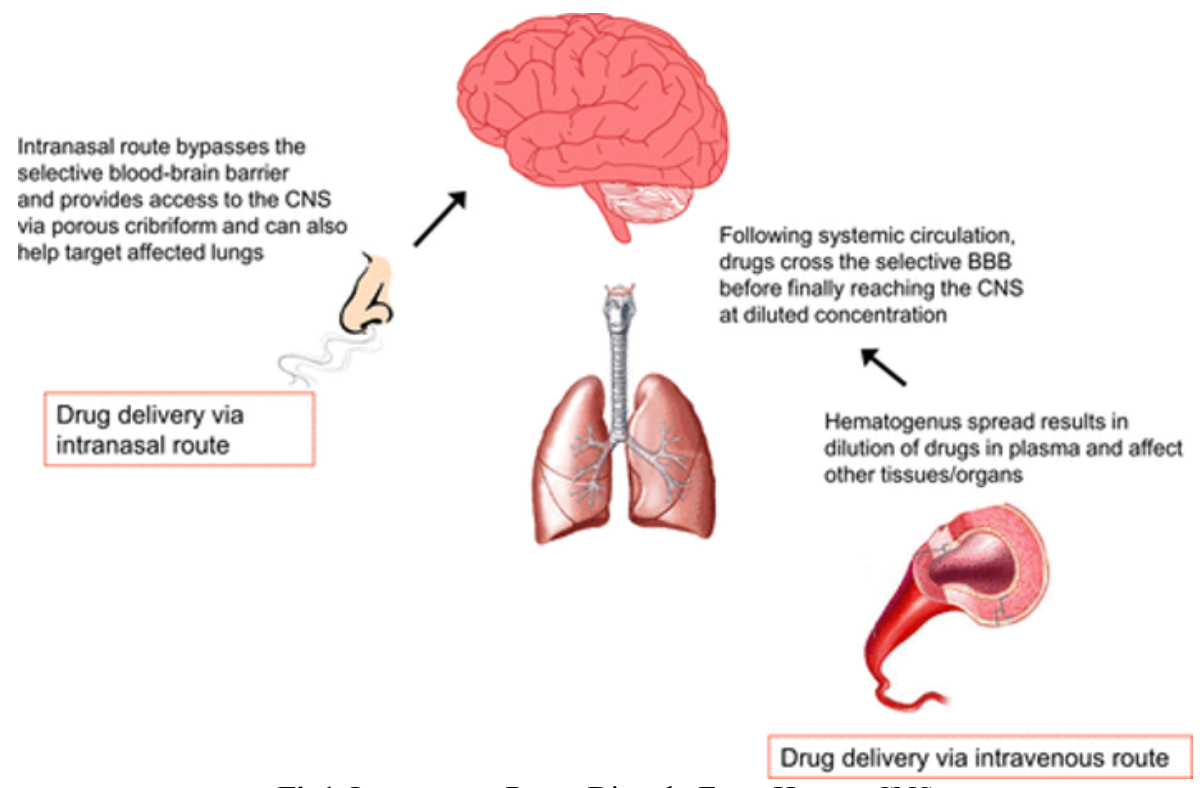

Fig1. Intravenous Route Directly Enter Human CNS

Patients who have T1DM are tending to have worse outcomes when they are diagnosed as COVID-19. However, a recent article conducted by Maja Bareti [16] pointed out a possible treatment to COVID-19-infected patients. Chloroquine treatment, which is also the treatment of autoimmune disorders, has been proved greatly success towards T1DM patients. The author made assumption whether the chloroquine treatment could be used clinically as a supplemented drug in the COVID-19 treatment. The author also pointed out chloroquine has immunomodulatory and hypoglycaemic effects. [16] The effective of chloroquine treatment is still remained uncertain at this point. Furthermore, another research paper conducted by Peter J. Richardson et al. raised more possibilities towards CNS penetration treatments. [17] 8 different drugs, each has different level of penetration. Based on the experiment results, Hydroxychloroquine and Baricitinib showed $21 \%$ and $20 \%$ penetration rate respectively $[18,19]$.

Table 3. Measured CNS exposures of potential COVID-19

therapeutics Conducted by Peter J. Richardson et al [17]

\begin{tabular}{|l|l|l|}
\hline & $\begin{array}{l}\text { Brain: } \\
\text { plasma ratio }\end{array}$ & Species \\
\hline Hydroxychloroquine & $21 \%$ & Mouse \\
\hline Baricitinib & $20 \%$ & Mouse \\
\hline Ruxolitinib & $3.5 \%$ & Mouse \\
\hline Remdesivir & $<5 \%$ & Macaque \\
\hline Tocilizumab & $0.1 \%$ & Macaque \\
\hline Lopinavir/ritonavir & $0.02 \%$ & Human \\
\hline
\end{tabular}


Then, the author indicated the Barictinib could be the most effective treatment to CNS based on its antiinflammatory properties and the AI-predicted viral activities. [17] Under Barictinib treatment, patients showed significant reduction of fever or cough and reduction of virial tire. [17] Baricitinib has now been tested clinically randomly across the United States. Patients who infected COVID-19 showed infection sights in CFS but some patients don't. Hence, treatment that penetrates blood-brain barrier might be the only effective way to clear out the entire virus infection inside human CNS.

However, another recent study raised concerns about using ACE inhibitors or angiotensin receptor blockers might be harmful to patients with diabetes during the COVID-19 treatment. [20] Since ACE2 is the receptor of COVID-19, the ACE inhibitors would cause the reduction of angiotensin II level by increasing the ACE2 level [21], therefore causing the virus easily bind to ACE2 to enter the human body. [20] Also, the release of angiotensin 1-7 in the brain stem leads to the activation of the sympathetic nervous system. This activation causes systemic vasoconstriction and the patients' blood pressure increases. Above all, the most important event is the increased sympathetic activity via the central stimulation, this activity increases pulmonary capillary leaking, causing the ARDS.

In conclusion, the effective treatments of human central nervous system infection are still remained uncertain. Just like the different ways of COVID-19 invade human CNS, two main ways of treatments are discussed in these sections which are intranasal route and CNS penetration. Each treatment has its strength and limitation: CNS penetration is more direct, since the CNS can directly enter CFS due to the direct penetration of blood-brain barrier. This treatment is effective to different circumstances; more importantly, CNS penetration has been put to clinical over the country and have solid experiments data to support it. On the other hand, the intranasal route can bypass the blood-brain barrier to enter the CNS, which means it is faster and more efficient. However, no clinical data are found in this method and this method is drug-dependent, which means only watersoluble drugs can be applied. Based on the current circumstances, injection might be the only viable clinical treatment.

\section{Discussion}

Although the infection of COVID-19 is usually identified in human respiratory system, central nervous system infection still takes up to $36 \%$ at some point. [10] The infection of central nervous system is mainly provoked by the interaction between the ACE2 and virus itself. The spike protein on the coronavirus interacts with the extracellular domains of transmembrane ACE2 proteins, followed by subsequent downregulation of surface ACE2 expression. [22] As for potential mechanism, clearance of infection site in human CNS could be the most effective way after infection. However, on the other hand, prevention of interaction between ACE2 and COVID-19
S-protein should also be the case. To disable the interaction, the blocking of receptor-binding domain on the spike protein on COVID-19 could be the way. Other than that, reduce the amount of ACE2 in human body can also reduce the chance of infection. Due to the wild spread of ACE2 in human body, infection could happen not only in central nervous system but also cardiovascular system. Inhibition on ACE2 should be the focus by many scientists in the future.

Generally speaking, only two possible treatments are effective now: one needs to penetrate the blood-brain barrier while the other goes through intranasal route. However, lack of clinical experiences and drug-dependent features of intranasal route makes it not really reliable at the moment. For clinical treatment of CNS infection, penetration should be the viable and effective method. For drugs that may cause the increase of ACE2, being harmful to diabetes patients, chloroquine therapy might not be effective since no clinical data express chloroquine can have any effects on the amount of ACE2.

It is quite obvious that the invasion of central nervous system may cause multiple complications such as dysfunction of peripheral organs (kidney, liver), systematic inflammation or the combination of both. The complications mentioned above can cause practicable long-term effects to human body. Since COVID-19 usually involves the activities of human innate system, which means the level of cytokines would increase to deal with the invasion of COVID-19, the increase level of COVID-19 may cause the depletion of $\mathrm{T}$ cell in human body. The exhaustion of $\mathrm{T}$ cells involves systematic inflammation which may cause severe neurodegeneration. The outcome of T cell exhaustion can last months or years and may cause Alzheimer's disease in the upcoming future. Although there are no clinical evidence about COVID-19 may cause severe neurodegeneration but the area of it is highly predictable and worth to pay attention to.

Since the invasion of CNS cause various complications, the invasion of $\mathrm{CNS}$ is proven to be responsible for acute respiratory failure. Medicine directly reach the central nervous system may help relive the syndromes in human lung. Although the psychological issues induced by COVID-19 are not directly linked to the virus itself, potential psychological issues cannot be overlooked at this point. The treatment in the future needs to combine psychiatric and medicine. The mental states of patients in quarantine needs to be taken care of in order to get remission.

In conclusion, COVID-19 mainly has three pathways to infect human central nervous system: 1. passage from the nasopharyngeal cavity to the olfactory bulb then reaching brainstem. 2. Virus reaches brainstem or CNS directly through bloodstream. 3 . The connection between lungs and brain make virus spread to human CNS. Currently, no effective drugs can be identified to treat CNS infection; more actions need to be taken to resolve this ongoing issue. 


\section{CONCLUSION}

In conclusion, the current findings relevant COVID-19 pathway towards human central nervous system is well discovered and studied. ACE2, as the main receptor for COVID-19, is responsible for the invasion of COVID-19 to human central nervous system. The virus invades ACE2 receptor via receptor binding domain (RBD) to reach human central nervous system. COVIS-19 invades human central nervous system in two ways: olfactory pathway and endothelial cells of the blood-brain barrier. The relevant treatment can be put in action by using injectable medicine such as Barictinib. Additionally, sending medicine via intranasal route can bypass the blood-brain barrier and send the medicine directly to central nervous system. However, this method lacks clinical example at the moment, future study is needed.

\section{ACKNOWLEDGEMENT}

I would like to express my appreciation to Dr. Deppmann for his constructive and valuable suggestions during the completion of this research work. His willingness providing his advice and time is greatly appreciated. I would also like to thank Ms. Yinggang Gao, Ms. Jiaqiong Sun and Mr. Max for their generous advice and assistance during the completion of this research paper. I would also likely to extend my thanks to all the authors of research paper for their strict attitude, professional technics and superior mind of chasing the truth for all human being. Finally, I want to express my thanks to my family members for the support they showed during the process of completing this research paper.

\section{REFERENCES}

1. Glass WG, Subbarao K, Murphy B, Murphy PM. Mechanisms of host defense following severe acute respiratory syndrome - coronavirus (SARSCoV) pulmonary infection of mice. J Immunol. 2004; 173:4030 - 4039 .

2. Li K, Wohlford - Lenane C, Perlman S, et al. Middle East respiratory syndrome coronavirus causes multiple organ damage and lethal disease in mice transgenic for human dipeptidyl peptidase 4 . J Infect Dis. 2016;213:712 - 722.

3. Paniz-Mondolfi A, Bryce C, Grimes Z, et al. Central nervous system involvement by severe acute respiratory syndrome coronavirus-2 (SARS-CoV-2). J Med Virol. 2020;92(7):699-702. doi:10.1002/jmv.25915

4. Li YC, Bai WZ, Hashikawa T. The neuroinvasive potential of SARS-CoV2 may play a role in the respiratory failure of COVID-19 patients. J Med Virol. 2020;92(6):552-555. doi:10.1002/jmv.25728

5. Li YC, Bai WZ, Hirano N, Hayashida T, Hashikawa T. Coronavirus infection of rat dorsal root ganglia: ultrastructural characterization of viral replication, transfer, and the early response of satellite cells. Virus
Res. 2012;163:628 - 635 .

6. Andries K, Pensaert MB. Immunofluorescence studies on the pathogenesis of hemagglutinating encephalomyelitis virus infection in pigs after oronasal inoculation. Am J Vet Res. 1980;41(9):1372 - 1378

7. Li YC, Bai WZ, Hirano N, et al. Neurotropic virus tracing suggests a membranous - coating - mediated mechanism for transsynaptic communication. J Comp Neurol. 2013; 521:203 - 212.

8. Netland, J., Meyerholz, D. K., Moore, S., Cassell, M., and Perlman, S. (2008) Severe acute respiratory syndrome coronavirus infection causes neuronal death in the absence of encephalitis in mice transgenic for human ACE2. J. Virol. 82 (15), 7264-75.

9. Mao, L., Wang, M., Chen, S., He, Q., Chang, J., Hong, C., Zhou, Y., Wang, D., Li, Y., Jin, H., and Hu, B.Neurological Manifestations of Hospitalized Patients with COVID-19 in Wuhan, China: a retrospective case series study. medRxiv, 2020.02.22.20026500

10. Saleki K, Banazadeh M, Saghazadeh A, Rezaei N. The involvement of the central nervous system in patients with COVID-19. Rev Neurosci. 2020;31(4):453-456. doi:10.1515/revneuro-20200026

11. Mao L, Jin H, Wang M, et al. Neurologic Manifestations of Hospitalized Patients With Coronavirus Disease 2019 in Wuhan, China [published online ahead of print, 2020 Apr 10]. JAMA Neurol. 2020;77(6):1-9. doi:10.1001/jamaneurol.2020.1127

12. Chamsi-Pasha MA, Shao Z, Tang WH (March 2014). "Angiotensin-converting enzyme 2 as a therapeutic target for heart failure". Current Heart Failure Reports. Springer Science and Business Media LLC. 11 (1): $58-63$.

13. Mascolo A, Urbanek K, De Angelis A, Sessa M, Scavone C, Berrino L, et al. (March 2020). "Angiotensin II and angiotensin 1-7: which is their role in atrial fibrillation?". Heart Failure Reviews. Springer Science and Business Media LLC. 25 (2): 367-380.

14. Siddiqui R, Khan NA. Proposed Intranasal Route for Drug Administration in the Management of Central Nervous System Manifestations of COVID-19. ACS Chem Neurosci. 2020;11(11):1523-1524. doi:10.1021/acschemneuro.0c00288

15. Chinese Preventive Medicine Association (2020) Guidance for Corona Virus Disease 2019, People's Medical Publishing House. http://www.pmph.com/ (accessed on 2020-08-06)

16. Maja Bareti. (May 2020). "Diabetes \& Metabolic Syndrome: Clinical Research \& Reviews". www.elsevier.com/locate/dsx (accessed on 2020-8-7)

17. Richardson PJ, Ottaviani S, Prelle A, Stebbing J, Casalini G, Corbellino M. CNS penetration of potential anti-COVID-19 drugs. J Neurol. 
2020;267(7):1880-1882. doi:10.1007/s00415-02009866-5

18. Gavegnano C, Haile WB, Hurwitz S, Tao S, Jiang Y, Schinazi RF, Tyor WR (2019) Baricitinib reverses HIV-associated neurocognitive disorders in a SCID mouse model and reservoir seeding in vitro. $\mathrm{J}$ Neuroinflamm 16(1):182. https ://doi.org/10.1186/s12974-019-1565-6

19. Jackson KM, Hansen RJ, Gustafson DL (2016) Pharmacokinetic and pharmacodynamic assessment of autophagy inhibition following hydroxychloroquine in mice. Cancer Res. https ://doi.org/10.1158/1538-7445.AM201 6-2084

20. Cure E, Cumhur Cure M. Angiotensin-converting enzyme inhibitors and angiotensin receptor blockers may be harmful in patients with diabetes during COVID-19 pandemic. Diabetes Metab Syndr. 2020;14(4):349-350. doi:10.1016/j.dsx.2020.04.019

21. Cure E, Cumhur Cure M. Comment on "Organprotective effect of angiotensinconverting enzyme 2 and its effect on the prognosis of COVID-19. J Med Virol 2020. https://doi.org/10.1002/jmv.25848.

22. Gheblawi M, Wang K, Viveiros A, et al. AngiotensinConverting Enzyme 2: SARS-CoV-2 Receptor and Regulator of the Renin-Angiotensin System: Celebrating the 20th Anniversary of the Discovery of ACE2. Circ Res. 2020;126(10):1456-1474. doi:10.1161/CIRCRESAHA.120.317015

23. Zhang XY, Huang HJ, Zhuang DL, et al. Biological, clinical and epidemiological features of COVID-19, SARS and MERS and AutoDock simulation of ACE2. Infect Dis Poverty. 2020;9(1):99. Published 2020 Jul 20. doi:10.1186/s40249-020-00691-6

24. Bao Y, Sun Y,Meng S, Shi J, Lu L (2020) 2019nCoVepidemic: address mental health care to empower society. Lancet (London, England) 395:e37-e38. https://doi.org/10.1016/s01406736(20)30309-3

25. Li H, Xue Q, Xu X. Involvement of the Nervous System in SARS-CoV-2 Infection. Neurotox Res. 2020;38(1):1-7. doi:10.1007/s12640-020-00219-8

26. Zhang XY, Huang HJ, Zhuang DL, et al. Biological, clinical and epidemiological features of COVID-19, SARS and MERS and AutoDock simulation of ACE2. Infect Dis Poverty. 2020;9(1):99. Published 2020 Jul 20. doi:10.1186/s40249-020-00691-6 